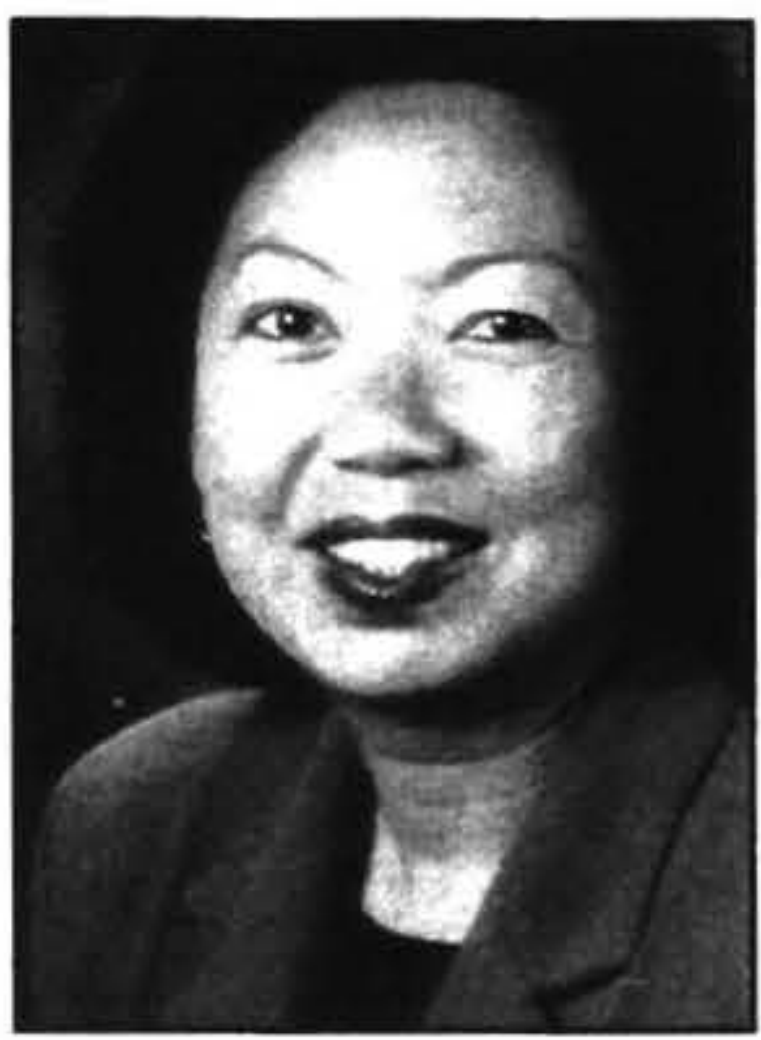

\title{
POST-SCHOOL EMPLOYMENT CHOICES OF EAST ASIAN ADOLESCENT MIGRANTS
}

\author{
Elsie S. Ho and Yunn-Ya Chen \\ Department of Geography \\ University of Waikato
}

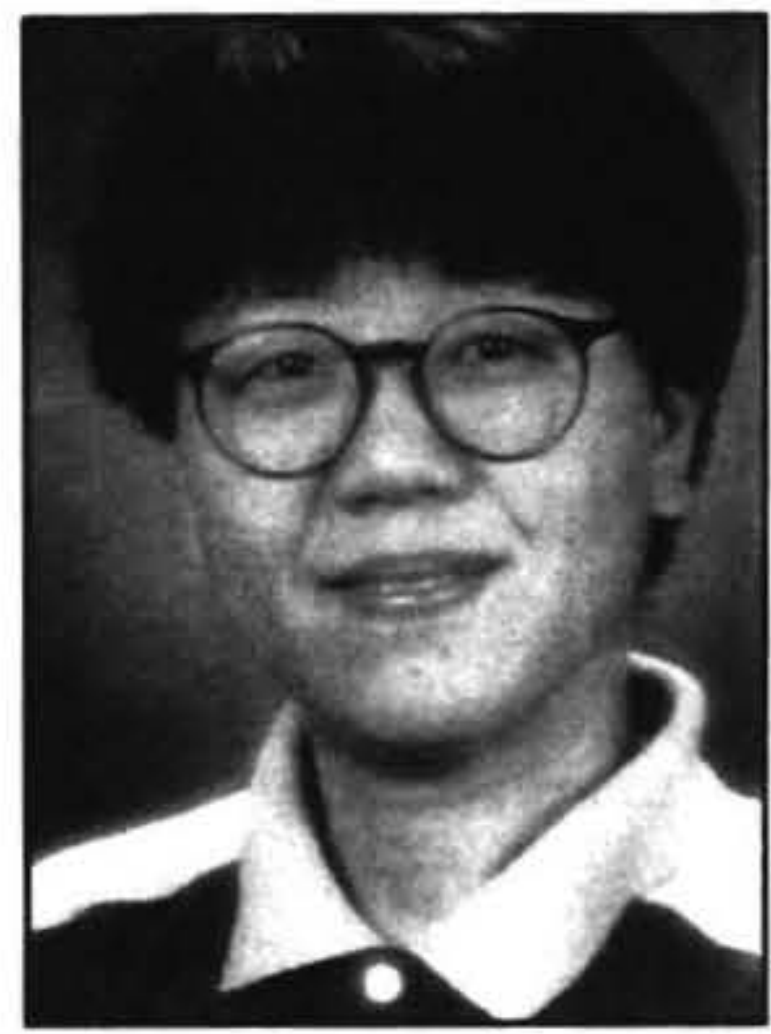

\begin{abstract}
Many immigrant children from Hong Kong, Taiwan and South Korea had general aspirations for the future which were similar to their parents' expectations. A survey of schools in Auckland in 1995 showed that a majority of them wished to complete university education, and aspired to managerial and professional occupations. However, they were more pessimistic than their parents about their employment prospects in this country. Only a small proportion of the young East Asian migrants wanted to work in New Zealand after they completed their education. A language barrier, racial discrimination and potential unemployment were cited as their main concerms.
\end{abstract}

The migration of large numbers of East Asian families to New Zealand in the 1990s is motivated, in part, by the desire to educate their children and build a better life for them (Ho and Farmer, 1994; Lidgard, 1996). Traditionally, the Chinese and Korean parents place great importance on their children's education (Jayasuriya, 1980; Zhu, 1992). They believe that the higher the education, the better the job opportunities and the more potential there is for a better future. For this reason parents are prepared to put a lot of effort and resources into getting the best possible education for their children. Many parents also have very high hopes for the future of their children.

High parental expectations can be seen by the children as encouragement and support, or as an unrealistic demand for achievement. In the case of immigrant children who face many uncertainties adapting to a new culture and society, as well as making decisions about what directions to take after they finish their schooling, the perception that parental support is available can function to enhance their capacity to cope with change (Ho, 1995). Unrealistic parental expectations can put immigrant children under great pressure and have a negative effect on their coping behaviour.

This paper is an attempt to contribute to an understanding of the integration of East Asian adolescent migrants in New Zealand. It reports on a questionnaire survey on adolescent migrants from Hong Kong, Taiwan and South Korea (Ho et al, 1996), and focuses on their educational ambitions and occupational aspirations, as well as their parents' expectations for them. Factors which may influence the East Asian adolescents' preferences for seeking employment in New Zealand or overseas are also discussed.

\section{The questionnaire survey}

The questionnaire survey was conducted in ten Auckland secondary schools between April and August 1995. Two self-completion questionnaires, one for the students and the other for their parents, were designed to provide information on the post-school education and employment choices of the East Asian adolescents, as well as their parents' expectations for them. In this report, 441 questionnaires returned by three groups of East Asian students, as well as 124 questionnaires completed by their parents, have been selected for analysis. The three groups of students are: Chinese immigrants born in Hong Kong, Chinese immigrants born in Taiwan, and Korean immigrants born in South Korea. Excluded from the survey were fee-paying students who were not immigrants. A student response rate of 77 percent was achieved in this survey, which was high for surveys of this nature. However, out of the 441 East Asian students who completed the questionnaires, only 124 parents (28\%) returned their questionnaires. The biggest obstacle to obtaining parents' responses in this survey was that the questionnaires were sent to the parents through their children in school $(\mathrm{Ho}, 1996)$. As a result, there was no assurance that the parents received our questionnaires. Another reason that could have contributed to the low response rate was that some parents were not living in New Zealand. There were 69 East Asian students who stated that both of their parents were not living in New Zealand most of the time in a year. Only 9 of these students' parents $(13 \%)$ returned their questionnaires. But among those students who stated that they were living with one or both parents, nearly one-third of their parents returned their questionnaires.

Table 1 presents the main characteristics of the East Asian 
Table 1. Main Characteristics of the East Asian Students in the Survey

\begin{tabular}{lrrrr}
\hline Characteristics & \multicolumn{1}{l}{ HK } \\
Chinese & $\begin{array}{l}\text { Taiwan } \\
\text { Chinese }\end{array}$ & $\begin{array}{l}\text { South } \\
\text { Korean }\end{array}$ & TOTAL \\
\hline Gender & & & & \\
& & & & \\
Male & 102 & 66 & 27 & 195 \\
Female & 118 & 81 & 47 & 246 \\
Total & 220 & 147 & 74 & 441 \\
& & & & \\
Age & & & & \\
15 years & 5 & 8 & 2 & 15 \\
16 years & 76 & 46 & 21 & 143 \\
17 years & 90 & 52 & 22 & 164 \\
18 years & 36 & 33 & 25 & 94 \\
19 years & 7 & 5 & 3 & 15 \\
Not stated & 6 & 3 & 1 & 10 \\
& & & & \\
Form level & & & & \\
Form 6 & 130 & 89 & 48 & 267 \\
Form 7 & 90 & 58 & 26 & 174 \\
Years in NZ & & & & \\
Under 1 year & 36 & 32 & 21 & 89 \\
1 - 2 years & 41 & 28 & 25 & 94 \\
2 - 3 years & 42 & 21 & 14 & 77 \\
3 - 4 years & 48 & 10 & 6 & 64 \\
4 - 5 years & 24 & 24 & 5 & 53 \\
Over 5 years & 29 & 32 & 3 & 64 \\
\hline & & & & \\
\hline
\end{tabular}

Source: Ho et al. (1996)

Table 2. Main characteristics of the East Asian parents who completed the questionnaires

\begin{tabular}{lrr}
\hline Characteristics & Males & Females \\
\hline Country of Origin & & \\
Hong Kong & 67 & 67 \\
Taiwan & 39 & 39 \\
South Korea & 18 & 18 \\
Total & 124 & 124 \\
& & \\
Age & & \\
30-39 & 0 & 8 \\
$40-49$ & 90 & 108 \\
50 and above & 31 & 7 \\
Not stated & 3 & 1 \\
& & \\
Education & & \\
University & 41 & 28 \\
Diploma or Certificate & 18 & 24 \\
Secondary & 25 & 46 \\
Primary and below & 9 & 22 \\
Not stated & 31 & 4 \\
& & \\
Years in NZ & & 25 \\
Under 1 year & 30 & 45 \\
1-3 years & 38 & 34 \\
3-5 years & 25 & 19 \\
Over 5 years & 14 & 17 \\
Not stated & 17 & \\
\hline Sorce & & \\
\hline
\end{tabular}

Source: Ho and Chen (1997) students. All respondents were studying in the sixth and seventh forms at the time of the survey and their ages ranged from 15 to 19 years. Nearly half of the Chinese students from Hong Kong and Taiwan had lived in New Zealand for over three years, but most of the Korean students had lived in New Zealand for under three years. Table 2 presents the main characteristics of the East Asian parents who completed the questionnaires. A majority of the parents were in the 40-49 age group, and almost half had tertiary education. It is of interest to note that not all parents answered every item in the questionnaires. About two-thirds of the questionnaires were filled in by the mothers of the students. Some of them did not provide information about their spouses' education level and their years of residence in New Zealand. The high percentage of item nonresponse suggested that not all parents were willing to provide information which they considered to be highly personal or sensitive.

Before we turn to the analysis of questionnaire responses, it should also be noted that, at the time this report was written, regional data from the 1996 Census of Population and Dwellings had not been released. Without these data, there was limited information available on which to judge the representativeness of the Hong Kong, Taiwan and Korean samples in this study. While not ensuring representativeness, using a relatively large sample and obtaining sample numbers from a wide range of schools located in different suburbs in Auckland, were the methods we used to reduce selection bias. For a full report on the background and methodology of the school survey, see Ho (1996).

\section{East Asian adolescents' aspirations for the future}

The educational and occupational aspirations of the three groups of East Asian students, as well as their preferences for seeking employment in New Zealand or overseas, are summarised in Tables 3 to 5 . A majority of either sex of the East Asian adolescents wished to get a university education (Table 3). Across groups, the largest proportion expressing an intention to get a $\mathrm{PhD}$ degree was found among the male students from South Korea (46\%). Fairly large proportions of the female students from Taiwan (37\%) and South Korea (32\%), as well as the male students from Taiwan (31\%), also expressed the wish to get a $\mathrm{PhD}$ degree. In comparison, smaller percentages of the Hong Kong Chinese students (24 percent of males and 17 percent of females) wished to do a doctoral degree.

As the East Asian adolescents had high educational expectations for themselves, it was not surprising that they also had high occupational aspirations. Over half of the Chinese adolescents from Hong Kong and Taiwan, and three out of four Korean students aspired to professional occupations such as those in medicine, engineering, architecture, accounting and law (Table 4). About one in four Chinese adolescents of either sex aspired to managerial positions, but only 4 percent of the female students from South Korea wished to become administrators and managers.

Despite their high educational and occupational aspirations, 
Table 3. Educational aspirations of the East Asian students (column percentages)

\begin{tabular}{lcccccc}
\hline & \multicolumn{2}{l}{$\begin{array}{l}\text { HK } \\
\text { Chinese }\end{array}$} & \multicolumn{2}{l}{$\begin{array}{l}\text { Taiwan } \\
\text { Chinese }\end{array}$} & \multicolumn{2}{l}{$\begin{array}{l}\text { South } \\
\text { Korean }\end{array}$} \\
Educational Aspirations & M & F & M & F & M & F \\
\hline PhD degree & 24 & 17.4 & 30.5 & 36.5 & 46.2 & 31.8 \\
Masters degree & 30.2 & 38.5 & 40.7 & 18.9 & 7.7 & 15.9 \\
Bachelor degree & 38.5 & 35.8 & 25.4 & 39.2 & 26.9 & 34.1 \\
Diploma or Certificate & 7.3 & 6.4 & 3.4 & 5.4 & 19.2 & 18.2 \\
F.7 & 0 & 1.8 & 0 & 0 & 0 & 0 \\
\hline
\end{tabular}

Source: Ho et al. (1996)

Table 4. Occupational aspirations of the East Asian students (column percentages)

\begin{tabular}{|c|c|c|c|c|c|c|}
\hline \multirow[b]{2}{*}{ Occupational Aspirations } & \multicolumn{2}{|c|}{$\begin{array}{l}\mathrm{HK} \\
\text { Chinese }\end{array}$} & \multicolumn{2}{|c|}{$\begin{array}{l}\text { Taiwan } \\
\text { Chinese }\end{array}$} & \multicolumn{2}{|c|}{$\begin{array}{l}\text { South } \\
\text { Korean }\end{array}$} \\
\hline & $\mathrm{M}$ & $\mathrm{F}$ & M & $\mathrm{F}$ & M & $\mathrm{F}$ \\
\hline Administrators \& managers & 18.8 & 24.6 & 20 & 19.8 & 0 & 4.3 \\
\hline Professionals & 55.4 & 45.8 & 55.4 & 58 & 74.1 & 76.6 \\
\hline Technicians & 13.9 & 11.9 & 12.3 & 6.2 & 22.2 & 10.6 \\
\hline Clerks & 1 & 1.7 & 0 & 2.5 & 0 & 0 \\
\hline Service \& sales workers & 1 & 0.6 & 3.1 & 6.2 & 0 & 0 \\
\hline Trades workers & 1 & 0 & 0 & 0 & 0 & 0 \\
\hline Undecided & 8.9 & 15.4 & 9.2 & 7.3 & 3.7 & 8.5 \\
\hline
\end{tabular}

Source: Ho et al. (1996)

Table 5. Countries Where East Asian Students Wished to Work (column percentages)

\begin{tabular}{|c|c|c|c|c|c|c|}
\hline \multirow[b]{2}{*}{ Country } & \multicolumn{2}{|c|}{$\begin{array}{l}\text { HK } \\
\text { Chinese }\end{array}$} & \multicolumn{2}{|c|}{$\begin{array}{l}\text { Taiwan } \\
\text { Chinese }\end{array}$} & \multicolumn{2}{|c|}{$\begin{array}{l}\text { South } \\
\text { Korean }\end{array}$} \\
\hline & M & $\mathrm{F}$ & M & $\mathrm{F}$ & $\mathbf{M}$ & $\mathrm{F}$ \\
\hline New Zealand & 16.4 & 16.4 & 17 & 11.1 & 39.1 & 17.7 \\
\hline Country of birth & 37.7 & 47.9 & 19.2 & 30.2 & 17.4 & 35.3 \\
\hline Other countries & 26.2 & 26.1 & 48.9 & 39.6 & 34.9 & 44 \\
\hline Undecided & 19.7 & 9.6 & 14.9 & 19.1 & 8.6 & 3 \\
\hline
\end{tabular}

Source: Ho et al. (1996)

only a small proportion of the East Asian adolescents indicated that they wished to work in New Zealand after they completed their education (Table 5). In general, males were more likely than females to prefer to work in New Zealand. A fairly large proportion of the adolescents from Hong Kong ( 38 percent of males and 48 percent of females) wished to go back to Hong Kong to work. Female students from Taiwan and South Korea were also more likely than the males to wish to return to their country of birth to work. Amongst the other countries where the East Asian adolescents would like to work, the USA was the most popular choice. About 19 percent of the students from South Korea, 14 percent of the those from Taiwan and 4 percent of the Hong Kong Chinese students indicated that they would like to work in the USA. Besides, 5 percent of the students from Hong Kong and Taiwan wished to work in Japan.

\section{Parental expectations}

Apart from getting information from the East Asian students, this research also asked the students' parents to state their educational and occupational expectations for their children. The main findings are summarised in Table 6.

Before we turn to a discussion of the East Asian parents' expectations for their children, it should be noted that out of the 441 East Asian students who completed the questionnaires, there were only 124 students and their parents who both returned their questionnaires. Because only 28 percent of the East Asian parents returned their questionnaires, and no speculations could be made about the remaining 72 percent who did not state their educational and occupational expectations for their children, the comparisons between the educational and occupational expectations expressed by the 
Table 6. Summary of findings of East Asian parents' educational expectation, occupational expectation and country where they preferred their children to work (\%)

\begin{tabular}{|c|c|c|c|c|c|c|}
\hline & \multicolumn{2}{|c|}{ HK parents } & \multicolumn{2}{|c|}{ Taiwan parents } & \multicolumn{2}{|c|}{ Korean parents } \\
\hline & Sons & Daughters & Sons & Daughters & Sons & Daughters \\
\hline \multicolumn{7}{|l|}{ Educational Expectations } \\
\hline $\mathrm{PhD}$ degree & 31 & 22.2 & 57.1 & 25 & 33.3 & 22.2 \\
\hline Masters degree & 41.4 & 40 & 28.6 & 28.6 & 33.3 & 22.2 \\
\hline Bachelor degree & 27.6 & 37.8 & 14.3 & 42.9 & 33.3 & 50 \\
\hline Diploma or below & 0 & 0 & 0 & 3.5 & 0 & 5.6 \\
\hline \multicolumn{7}{|l|}{ Occupational Expectations } \\
\hline Administrators \& managers & 25 & 30 & 15.4 & 17.9 & 0 & 5.9 \\
\hline Professionals & 41.7 & 20 & 53.8 & 42.9 & 66.7 & 41.2 \\
\hline Technicians & 0 & 7.5 & 0 & 7.1 & 33.3 & 11.8 \\
\hline Clerks & 0 & 0 & 0 & 0 & 0 & 0 \\
\hline Service \& sales workers & 4.2 & 0 & 0 & 7.1 & 0 & 0 \\
\hline Trades workers & 0 & 0 & 0 & 0 & 0 & 0 \\
\hline Others (incl. unidentifiable) & 0 & 2.5 & 7.7 & 3.6 & 0 & 11.8 \\
\hline Not specified & 29.1 & 40 & 23.1 & 21.4 & 0 & 29.3 \\
\hline \multicolumn{7}{|c|}{ Countries Where They Preferred Their Children To Work } \\
\hline New Zealand & 50 & 51.1 & 45.5 & 46.4 & 33.3 & 68.7 \\
\hline Country of origin & 14.3 & 17.8 & 9 & 14.3 & 0 & 12.5 \\
\hline Other countries & 25 & 17.8 & 18.2 & 28.6 & 33.4 & 6.3 \\
\hline Not specified & 10.7 & 13.3 & 27.3 & 10.7 & 33.3 & 12.5 \\
\hline
\end{tabular}

Source: Ho et al. (1996)

students and those given by their parents should serve only as guidelines for further inquiries.

Nearly all the East Asian parents who stated their educational aspirations for their children wanted their sons and daughters to get a university degree (Table 6). However, more Korean students, rather than their parents, wished to get a $\mathrm{PhD}$ degree. In contrast, more Hong Kong parents, rather than the students, wanted their children to get a doctoral degree. Taiwanese parents had much higher expectations for their sons than daughters.

Nearly half of the parents from Taiwan and South Korea and about 30 percent of the parents from Hong Kong, who responded to the question about preferred occupations for their children, expected their children to have professional careers, such as doctors, dentists, lawyers, engineers, architects and computing professionals (Table 6). In addition, one in four of the parents from Hong Kong and one-sixth of those from Taiwan expected their children to have managerial occupations. On the whole, more parents from Hong Kong, rather than the students themselves, expected their children to have managerial occupations. On the other hand, more students from Taiwan, rather than their parents, aspired to managerial careers. More Korean students rather than their parents wished to have professional occupations.

Table 6 also shows that the percentages of East Asian parents who would like their children to work in New Zealand were much higher than those expressed by the students (Table 5). On the other hand, the percentages of parents who would like their children to return to their original countries to work were much lower than those given by the students.

\section{Worries about seeking employment in New Zealand}

The discussion so far suggests that a majority of the East Asian adolescents shared the high aspirations which their parents had for them. Many hoped that they would go as far as they could in the education system, and that they would also get a good job which would enable them to become financially independent and to live a good life in the future. Because education is hihgly valued in both the Chinese and Korean cultures these results are hardly surprising. However, there were differences between the parents and their children as far as the question about preferred country of work was concerned. Over half of the East Asian parents would like their children to work in New Zealand rather than overseas, but only a small proportion of the East Asian adolescents wanted to work in NewZealand. The reasons for this difference will now be explored.

A language barrier, racial discrimination and potential unemployment were the main worries the East Asian students had as they considered options for employment in New Zealand (Figure 1). A majority of the Korean adolescents of either sex worried about their own language competency. Female students from South Korea were also more likely than the males to worry about racial discrimination and potential unemployment. Over half of the male students from Taiwan considered that racial discrimination was the 
Figure 1. Worries East Asian students had about future employment in New Zealand

(a) Males

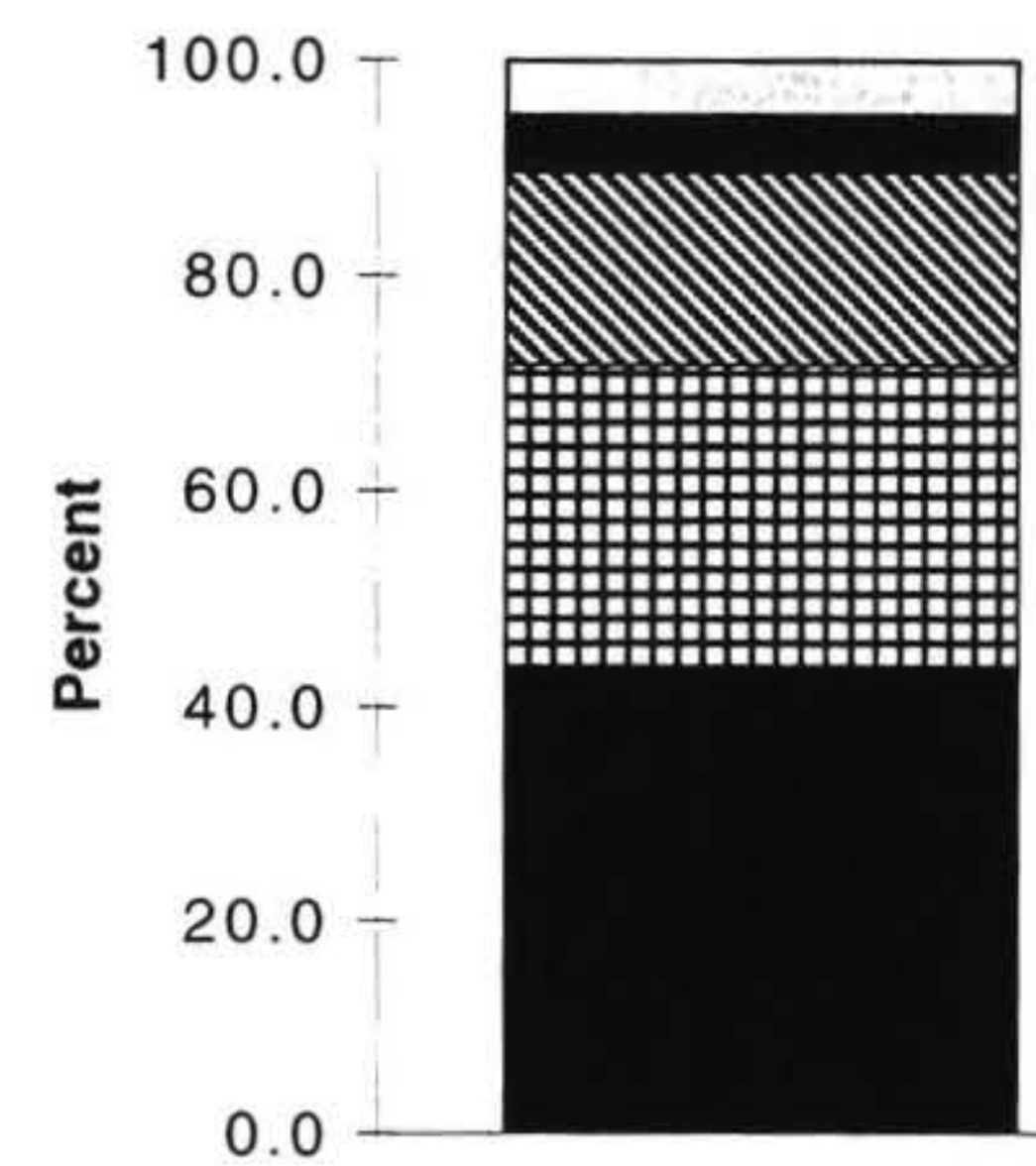

HK Chinese

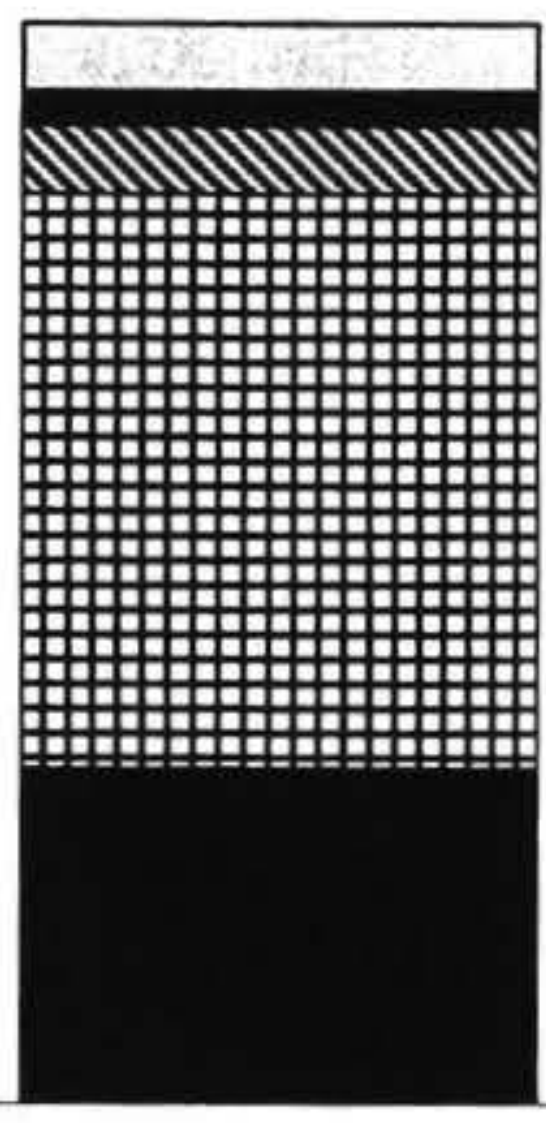

Taiwan Chinese

Student Group

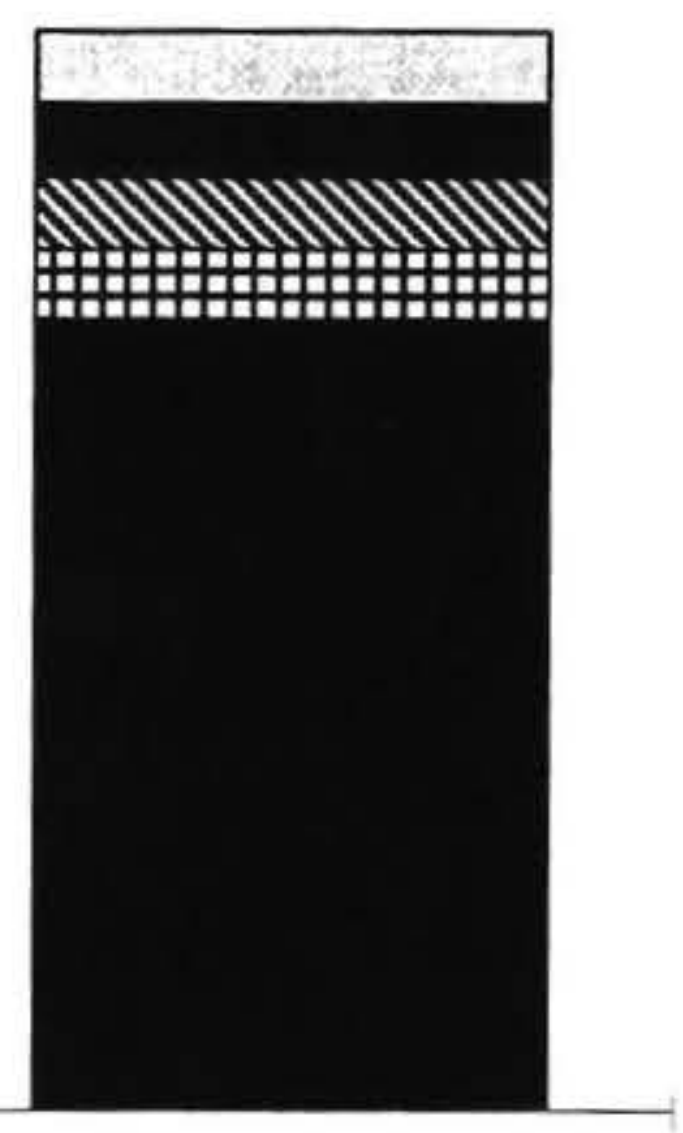

Korean

(b) Females

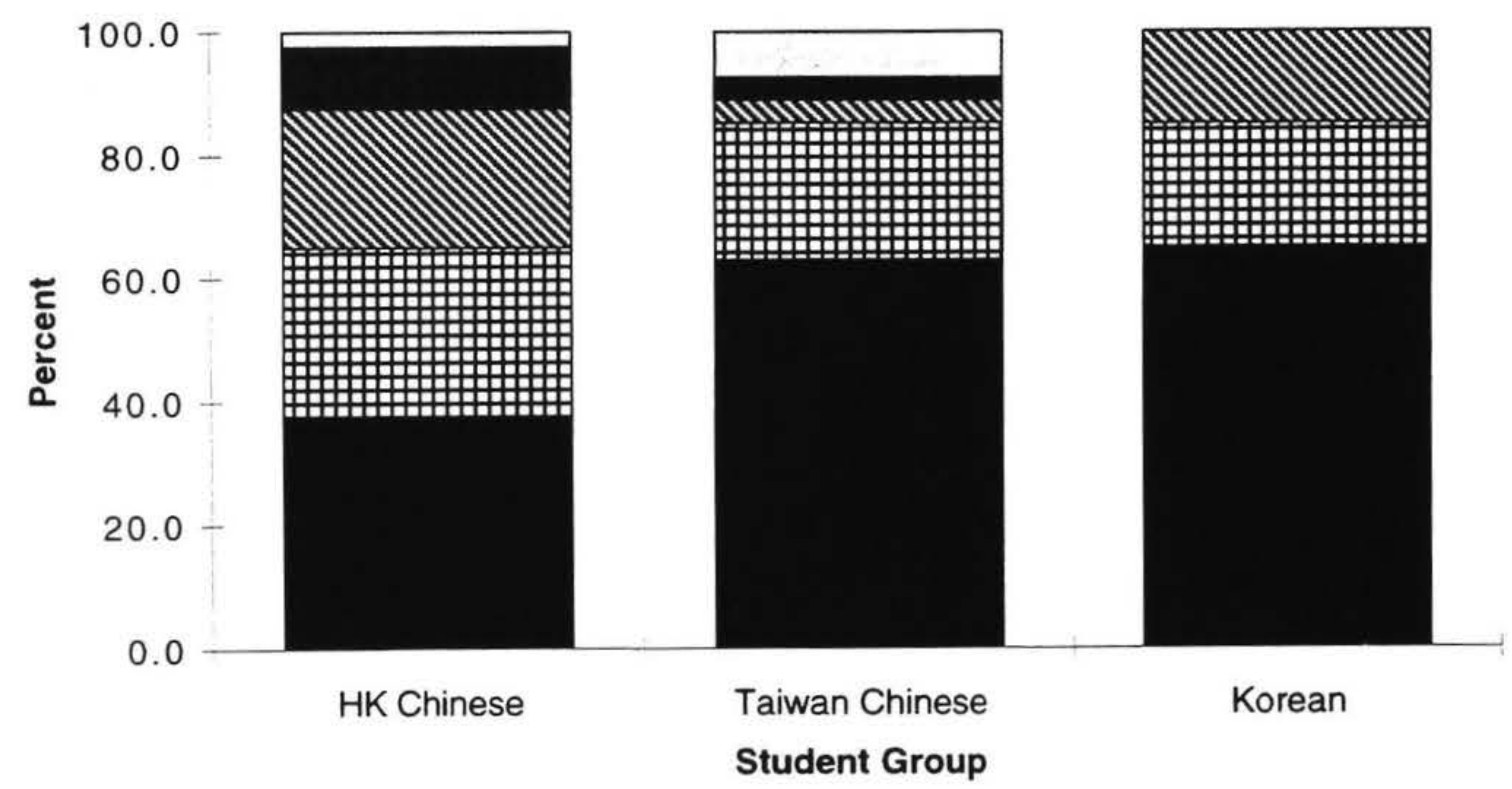

Language $\mathbb{\boxplus}$ Racial Discrimination $\$$ Unemployment Suitable Job Choice $\square$ Other 
main problem they would face in seeking employment in New Zealand, but female students worried about their own language ability more than racial discrimination. For the Hong Kong Chinese students, the males were more likely than the females to cite language and racial discrimination as their main concerns, but the females were more likely than the males to worry that they could not find any job in New Zealand after they finished their studies.

Compared with their children, East Asian parents were less pessimistic about their children's employment prospects in this country. Smaller proportions of them expected their children to have problems finding jobs in New Zealand because of language difficulties and racial discrimination. Some parents thought that getting a suitable employment, and their children's own personal problems such as their lack of self-confidence or interpersonal skills, would be the main problems their children had to face in finding employment in this country (Figure 2).

As the East Asian adolescents were worried about their own English language competence, as well as racial prejudice and the lack of employment opportunities in New Zealand, it was not surprising that many of them did not want to work in this country. The East Asian adolescents' concern about their employment prospects in New Zealand was brought up for discussion in the follow-up group interviews carried out as part of the school survey (Ho, 1996). During the discussions, large numbers of East Asian adolescents indicated that they wished to seek employment in countries where they perceived there would be more job opportunities and better employment prospects than in New Zealand (Ho et al, 1996, p.48). Among these students, some wished to return to their country of birth to work, with the expectation that there would be "no language barriers and no problem of racial discrimination", and that they could also earn more money. However, some East Asian adolescents were uncertain whether finding work overseas was a better choice than looking for jobs in New Zealand. Their main concerns were the practical difficulties of getting good positions in their country of birth as they no longer had the social connections there. In addition, their New Zealand qualifications might not be recognised in the countries where they wished to work. Consequently, a number of young East Asian students were of the view that they might decide to stay in New Zealand if they could find suitable employment in this country.

As mentioned above, higher salary, a wider range of job choices and better job conditions were part of the attraction of looking for jobs overseas. Apart from better career opportunities, a number of young East Asian migrants were also motivated to seek employment overseas to gain more enriching life experiences, with a view to returning to New Zealand after some years (Ho et al, 1996, p.51). These motives are similar to the motivation for "overseas experience" among European New Zealanders (Lidgard, 1992).

\section{Figure 2. Worries East Asian parents had about their children's future employment in}

New Zealand

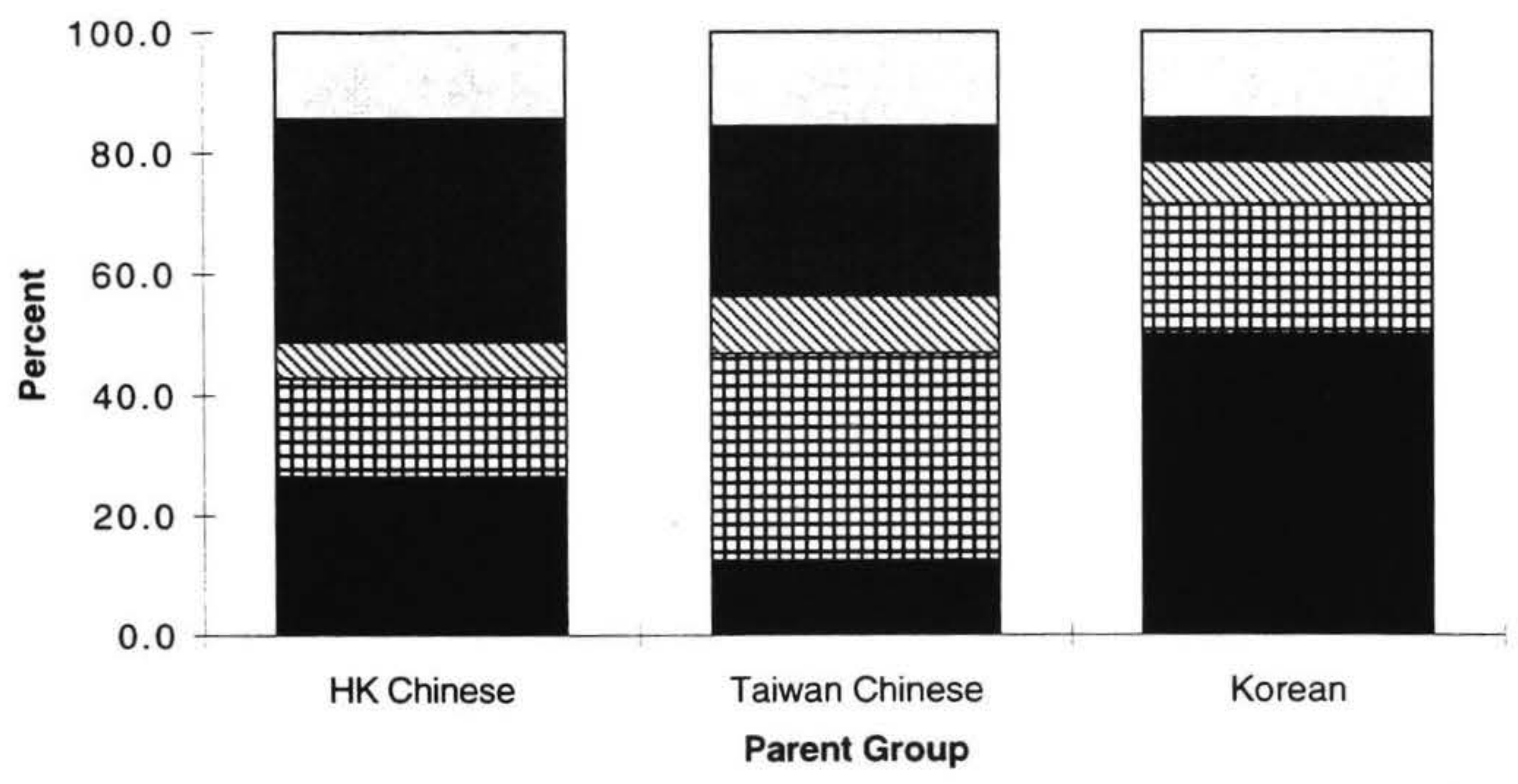

- Language $\mathbb{\boxplus}$ Racial Discrimination $\mathbf{Q}$ Unemployment $\mathbf{a}$ Suitable Job Choice $\square$ Other 


\section{Summary and discussion}

Because a good education for children is considered of fundamental importance in both the Chinese and Korean cultures, East Asian parents have high educational expectations for their children. As well, as migrant parents, many of whom are well-educated but have lost status in coming to their new country, they also tend to place great hopes in their children's future through achievements in the education system (Hartley and Maas, 1987; Lidgard, 1996; Marjoribanks, 1980). Most migrants see education as a way of establishing some security in the future when opportunities and networks which existed in the home country are no longer present.

Our research has shown that young East Asian migrants from Hong Kong, Taiwan and South Korea had high aspirations for the future which were similar to what their parents wanted for them. To a large degree the young people accepted their parents' values concerning the importance of education, and were prepared to work hard to succeed at school, and then to enter an occupation which could provide them with satisfaction and financial security.

As far as specific occupations were concerned, many East Asian adolescents who were about to leave school were considering a fairly limited range of occupations. Engineers, architects, doctors, dentists and lawyers were the favoured occupations of the East Asians. Parental aspirations for their children to attain these high status occupations seemed to have some influence on what the children wanted for themselves. Besides, there were other factors which might contribute to the limited range of career options considered by the East Asians. Many East Asian students as well as their parents, especially those who had only lived in this country for a short time, had little knowledge about the job choices available in New Zealand (Ho et al, 1996, p.28). For these students, their favoured careers tended to be those which were familiar in their country of origin. Apart from a lack of information about a wide range of occupations, some East Asian adolescents considered that their limited English language ability also posed restrictions on their post-school career options.

What is also of concern is the large proportion of the East Asian adolescents who expected to face serious problems when they looked for jobs in New Zealand. Many of them were worried that they could not find any jobs in this country after they finished their studies. Some were also worried that racial discrimination and a language barrier would further increase their difficulties of getting a job. Apparently, the worries these young migrants had about future employment in New Zealand were influenced by the unsuccessful experiences of their parents and close relatives in finding jobs in this country. ${ }^{1}$ Even thought many of them were prepared to work harder, get higher educational qualifications and acquire specialised occupational skills, they were still unsure if they would have a better chance of finding a job in New Zealand. Because of the uncertainty about future employment prospects in New Zealand, many young East Asian adolescents were keeping all options open and were pre- pared to go where they could find work. These findings have broad implications for New Zealand's society and economy. Given the growing economic importance of Asia to New Zealand, we need a highly skilled and hardworking labour force with good knowledge and understanding of the economic and cultural backgrounds of Asian countries. If large proportions of East Asian adolescents are not prepared to join our labour force after they finish their education, we will lose a valuable resource in this regard.

\section{Future research}

Although there have been significant immigrant flows into New Zealand from Asian countries during the last decade, Asians still constitute a minority within New Zealand's total population. Many New Zealanders have little direct contact with the people from countries in Asia, and few have a knowledge and understanding of these newcomers' diverse backgrounds, languages, cultures and lifestyles. The present research provides some much-needed empirical data on the aspirations and future plans of young East Asian migrants. A follow-up study is needed to provide further information regarding the directions migrant students eventually take after they finish their education, and some of the factors which influence their decision-making process.

Research is also needed to find out if migrant students, as well as their parents, have access to relevant information and knowledge about future education and career options in New Zealand. It is important to explore if parents have realistic assessment of their children's performance and abilities in school, as parents often play an important role in assisting their children make decisions for the future. It is also important to explore if career counselling services are available at school to deal with the special needs of migrant students, how often the students use these services and whether or not they find the services helpful. As our research revealed, migrant students tend of have a lot of worries about their future during the transition from school to work. Increased communication between home and school and greater access to relevant information are ways that may increase migrant students' post-school employment options and facilitate their integration into New Zealand's society and workforce.

\section{Acknowledgements}

This study forms part of two larger research projects, the Demographic Crossroads Programme and the New Demographic Directions Programme, which are being carried out at the University of Waikato with financial support from the Foundation for Research, Science and Technology. The authors wish to acknowledge the assistance received from the pupils, their parents, school principals and teachers of several Auckland secondary schools where the survey was undertaken; and Ms Jannie van Hees, New Settlers and Multicultural Education Co-ordinator of the Education Advisory Service in Auckland. The advice, support and assistance of Professor Richard Bedford, Co-ordinator of the migration projects, and Mrs Jacqueline Lidgard and Ms Joanne Young, members of the research team is gratefully appreciated. 


\section{Notes}

1. A brief report of a study on the employment experiences of East Asian migrants is presented at the LEW7 conference (Ho \& Lidgard, 1997).

\section{References}

Hartley, R. and Maas, F. 1987 Getting a lot further: Some factors influencing decisions which ethnic families make about children's schooling and postschool futures Jean Gordon Government Printer, Melbourne.

Ho, E.S. 1995 The challenge of culture change: The crosscultural adaptation of Hong Kong Chinese adolescent immigrants in New Zealand. Unpublished DPhil thesis, University of Waikato, Hamilton.

Ho, E.S. 1996 Researching post-school education and employment choices among Asian adolescent migrants: A report on methodological issues Population Studies Centre Discussion Paper Number 14, University of Waikato, Hamilton.

Ho, E.S. and Chen, Y.Y. 1997 New migrants from East Asia: Family backgrounds and adaptation in New Zealand Population Studies Centre Discussion Paper (in preparation), University of Waikato, Hamilton.

Ho, E.S., Chen, Y.Y., Kim, S.N. and Young, J. 1996 In search of a better future: Report of a survey on post-school education and employment choices among Asian adolescent migrants Population Studies Centre Discussion Paper Number 17, University of Waikato, Hamilton.

Ho E.S. and Farmer, R. 1994 The Hong Kong Chinese in Auckland. In Skeldon, R (ed) Reluctant exiles? Migration from Hong Kong and the new overseas Chinese M.E. Sharpe, New York.

Ho E.S. and Lidgard, J.M. 1997 Give us a chance: the employment experiences of new settlers from East Asia. In Morrison, P.S. (ed.) 1997, Labour Employment and Work in New Zealand, Proceedings from the Seventh Conference. Victoria University of Wellington.

Jayasuriya, JE 1980 Education in Korea - A Third World success story AssociatedEducational Publishers, Colombo, Sri Lanka.

Lidgard, J.M. 1992 Return migration of New Zealanders: A rising tide? Unpublished Masters thesis, University of Waikato, Hamilton.

Lidgard, J.M. 1996East Asian migration to Aotearoa/New Zealand: Perspectives of some new arrivals Population Studies Centre Discussion Paper Number 12, University of Waikato, Hamilton.
Marjoribanks, K. 1980 Ethnic families and children's achievements George, Allen and Unwin, Sydney.

Zhu, W. 1992 Confucius and traditional Chinese education: an assessment. In Hayhoe, R (ed) Education and modernisation: the Chinese experience Pergamon Press, Oxford.

\section{Authors}

Elsie Ho is a research fellow and $\mathrm{Yunn} \mathrm{Ya}$ Chen is a research assistant at the Department of Geography at the University of Waikato, Private Bag 3108, Hamilton. 